\title{
SEEING IS BELIEVING: FACIAL APPEARANCE, CREDIBILITY, AND ATTITUDE CHANGE
}

\author{
Sheila Brownlow
}

ABSTRACT: One-hundred twenty-eight subjects (64 female, 64 male) viewed either a babyfaced or maturefaced female speaker delivering a persuasive communication, and also received information designed to make the speaker seem either untrustworthy or inexpert. Subjects indicated how much they agreed with the speaker's position and completed other measures concerning her appearance and their perceptions of her speech. Babyfaced speakers induced more agreement with their position than did maturefaced speakers when trustworthiness was in question, presumably because babyfaced speakers still appeared honest due to their babyish facial features. Conversely, maturefaced speakers produced more attitude agreement as compared to babyfaced speakers when expertise was questioned, perhaps because knowledgeability was still communicated via their mature countenance. Attitude change was not related to perceived likability, age, attractiveness, or communication skills of the speakers, or subjects' interest in the topic.

Over 80 million people watched at least one of the 1960 KennedyNixon television debates. Those who listened to them on the radio tended to think Richard Nixon had outdone the youthful, inexperienced JFK. The Republican's words carried more weight. Those who watched on television, however, proclaimed Kennedy the winner. His words were less important than his warmth [and] his sincerity. ... All of these qualities came across on television.

-Krauss, in Davis \& Baran (1981, pp. 103-104)

Although the advent of television did not mark the beginning of formal study of the manner in which qualities of persuasive sources influence us, it did serve as a catalyst to elucidate the nature of the relationship between physical appearance and persuasion. Indeed, score of studies conducted since the early 1960 s have examined the effects of readily discernible qualities of sources, particularly physical attractiveness, on their ability to mod-

Sheila Brownlow is affliated with Catawba College, Salisbury, North Carolina.

Requests for reprints should be addressed to Sheila Brownlow, Catawba College, Salisbury, NC 28144. 
ify attitudes (see Chaiken, 1986, for a complete review). However, there are other aspects of physical appearance, such as facial babyishness, which have been shown to affect our impressions of others (Berry \& McArthur, 1986). Because the impact of this component of physical appearance has received no attention in the persuasion literature, the present focus concerns the ways in which facial appearance affects attitude modification.

Physical appearance is not the only source of information about a persuasive source that influences attitude change. Source trustworthiness (or objectivity) and expertise (or knowledgeability) contribute to credibility, and both of these components influence attitude modification to the extent that those judged to be trustworthy or expert (or both) are likely to produce both immediate attitude change (McGinnies \& Ward, 1980), and behavioral compliance (Sternthal, Phillips, \& Dholakia, 1978). Sources will be judged as trustworthy if they argue against their own self interest (Walster, Aronson, \& Abrahams, 1966), or if they are judged to be honestly communicating facts that they consider to be valid. Expert sources are typically described as having high-status occupations that make them appear quite knowledgeable (McGinnies \& Ward, 1980), are perceived to have valid information, and seem to be aware of the correct stance relevant to the issue at hand (Hovland \& Weiss, 1951). The persuasive effects of credibility remain even when an audience is not completely attentive to the message (Eagly \& Chaiken, 1984), although the effects are not as strong when the content of the message being communicated is of personal relevance to the perceiver (e.g., Petty, Cacioppo, \& Goldman, 1981).

Research examining the persuasive effects of sources has often relied on providing targets with biographical information about the source. In the real world, impressions of sources can be shaped in a more natural way, such as via physical appearance. As noted earlier, attractive communicators are more persuasive than their unattractive counterparts (cf. Chaiken, 1979; Dion \& Stein, 1978). Eagly and Chaiken (1984) have noted that attractiveness is a quality that is highly salient to perceivers, and may precipitate a transfer of positive affect. That is, we like attractive people, and are happy to be in agreement with them. When attractiveness is not made salient, as when a persuasive communication is presented via a written modality, the advantage of attractiveness is lost. The persuasive impact of attractiveness also diminishes when targets are truly interested in the topic presented (Eagly and Chaiken, 1984).

Might other physical characteristics of a source make a contribution to credibility, and, in turn, persuasive ability? Research concerned with facial appearance and impressions has demonstrated that adults whose faces 
have babyish features are also perceived to have babyish psychological qualities (Berry \& Brownlow, 1989; Berry \& McArthur, 1985). Those with babyish features are judged to be more honest, kind, warm, and naivebut less intellectually astute-than those who have more mature faces. One explanation for these perceptions of babyfaced people comes from Fridlund (1991), who theorizes that there is a propensity for people to expect infants to be guileless and innocent. Another explanation has been offered by Berry and McArthur (1986), who postulate that perceivers detect certain physical qualities in others which might specify behavioral propensities. Indeed, youthful qualities in women are desired when males consider the ideal mate, presumably because these qualities specify fertility and/or reproductive value (Buss, 1989), and the mixture of both neonatal and mature features in the faces of attractive women may specify both warmth and sophistication (Cunningham, 1986).

Our impressions of people varying in facial babyishness are likely to affect our judgments in persuasive situations, as babyfaced people, who are perceived as honest, may similarly be viewed as trustworthy. Maturefaced people, who are seen as intellectually astute, may be perceived as knowledgeable and expert. One situation where the impressions of credibility are paramount is the television commercial, where advertisers spend a good deal of time and money finding the "ideal" spokesperson for their products. Because perceptions of trustworthiness and expertise are integral components in persuasive situations, commercial spokespersons might be cast on the basis of how well these qualities are conveyed by facial appearance. Indeed, Brownlow and Zebrowitz (1990) found that babyfaced people were cast into commercials in which the basis of credibility was trustworthiness, whereas maturefaced people were cast into commercials in which the basis of credibility was expertise. While the results revealed the favored combinations of credibility and facial appearance, the study did not explicitly assess whether credibility can be communicated directly via facial appearance; nor did it examine the effect on attitude change of facial appearance-based credibility.

The present study was designed to examine the manner in which facial appearance and credibility information interact to influence attitude change. This experiment assessed the impact of a source's facial structure and her perceived credibility in the following way: Subjects saw either a babyfaced or maturefaced female' speaker delivering a persuasive message, and they received information about her which was designed to make her seem either untrustworthy or inexpert. It was predicted that ques-

'Females were used due to availability, rather than for any theoretical reason. 
tioning the trustworthiness of babyfaced speakers would be less damaging to their ability to induce agreement compared to questioning the trustworthiness of their maturefaced counterparts, as trustworthiness would still be communicated by the facial structure of babyfaced speakers. Similarly, casting doubt on the expertise of maturefaced speakers would be less detrimental to their ability to induce agreement as compared to casting doubt on babyfaced speakers' expertise, as expertise and knowledgeability would still be communicated by the facial appearance of maturefaced speakers.

\section{Method}

\section{Pretesting and Selection of Stimulus Materials}

Audio communication. A female speaker with no obvious traces of regional accent in her speech recorded a communication containing three brief arguments explicating the speaker's supposed opposition of tuition increases for out of state students at a small college in a distant state. Pilot testing indicated that the arguments contained in the communication were of only moderate strength and of only minor interest to the subject population.

Speakers. Four females of differing levels of facial babyishness were chosen to serve as speakers. Data regarding others' perceptions of the facial babyishness and attractiveness of each were available. Two of these women were chosen from a study by Berry and Brownlow (1989), where 9-point scales were used to judge the babyfacedness and attractiveness of twenty-four female targets. These judgments were highly reliable, and yielded a mean sample rating of $M=4.52(S D=1.00)$ for babyfacedness and $M=4.35(S D=1.25)$ for attractiveness. The first speaker drawn from this sample had a mean babyfacedness rating of $M=3.42$ and a mean attractiveness rating of $M=3.64$, and was thus deemed maturefaced. The second speaker drawn from this sample had a mean babyfacedness rating of $M=7.96$ and a mean attractiveness rating of $M=4.83$, and was thus deemed babyfaced. The facial appearance judgments were more than one $S D$ away from the sample mean while the attractiveness judgments were within one $S D$ of the sample mean; thus those women chosen represented extremes on the facial appearance dimension but were not extreme on the attractiveness dimension.

Two more speakers were chosen after participating in a study conducted by Berry (1990) where their photographs had been rated with 9-point scales on the babyfacedness and attractiveness dimensions. The 
mean babyfacedness ratings for the two women chosen were $M=2.58$ and $M=5.80$ (sample range Ms 2.24 to 5.94 with a grand mean of $4.48 ; S D$ ratings not available). Given that one woman's babyfacedness was perceived to be high compared with the rest of the sample, while the other woman's babyfacedness was perceived to be low, these speakers were deemed to be appropriately babyfaced and maturefaced. The mean attractiveness rating for the maturefaced speaker was 3.67 , and 4.00 for the babyfaced woman (sample range $M s=2.10$ to 7.26 with an overall mean of 4.49). Thus, the speakers chosen from this sample were different on the dimension of babyfacedness, but similar with regard to attractiveness.

Stimulus videotape. The four women chosen as speakers were videotaped "lip syncing" the previously described audio communication. Each was taped without makeup or jewelry, with her hair pulled back, and wearing the same black jacket over her clothing. During the taping, speakers sat against a neutral colored wall, eight feet from a VHS camcorder mounted on a tripod. The camera remained stationary but the zoom was adjusted so that each woman was taped from the shoulders to the top of the head. A tape recorder was placed next to the camcorder microphone, and the recorded communication was played while speakers lipsynced the communication.

Pilot test of stimulus videotape. Forty (20 female, 20 male) students in introductory psychology served as subjects in a pretest. These subjects were recruited to ensure that, in absence of the credibility manipulation, the baby- and maturefaced speakers were not differentially able to induce attitude change. Participants were told that they would be evaluating a practice student campaign speech made by a woman running in a student election at a small college in Texas. After being told that the experiment concerned unbiased evaluations of student speeches, subjects were seated five to six feet away from a black and white television monitor, experimental consent was obtained, and the rating procedures were explained. Participants were told to examine the first page of their response booklet for some information about the candidate, where they read that the candidate's name was Anne Greeley and that her age was 20. After watching the speaker deliver her message, subjects used 9-point scales to indicate how much they agreed with the speaker's position regarding prohibiting a raise in tuition (scale endpoints labeled "disagree completely/agree completely"), and how trustworthy and expert they perceived her to be (scale endpoints labeled "not at all trustworthy [expert]/very trustworthy [expert]"). 


\section{Main Experiment}

Subjects. One hundred twenty-eight (64 male, 64 female) volunteers from introductory-level psychology courses at two colleges served as subjects in the experimental conditions. Male and female subjects were randomly assigned to view one of the four speakers under one of two questioned credibility conditions, yielding a 2(2) (Exemplar of Speaker Nested in Face Type) X 2 (Subject Sex) X 2 (Credibility Condition) between-subjects design.

Procedure. The procedure outlined in the pilot test of the videotape was again utilized for subjects participating in the experimental conditions. Subjects in the not trustworthy condition ( $n=64 ; 32$ females and 32 males) watched the speaker deliver the speech while bogus biographical information about the speaker designed to cast doubt on her objectivity, or trustworthiness, was presented in written form on the first page of the response booklet. This was accomplished by telling subjects that she was a student at a small Texas college, but her homestate was Wisconsin. Given that the speaker was advocating a prevention of tuition increases for out of state students, she was arguing in her own self interest, and thus would seem untrustworthy (cf. McGuire, 1985). Other biographical information included her supposed name (Anne Greeley), her major (Psychology), her age (20), her class (Junior), and her University activities (Member, Out-ofState Student Committee). The other biographical information was designed to make the speaker appear to be competent enough to discuss the topic by demonstrating that she had had both experience as a student and experience on a committee.

Experimental participants in the not expert condition $(n=64 ; 32$ males and 32 females) heard the speech while bogus biographical information, designed to make the speaker seem inexpert, was presented via written information on the first page of their response booklet. Subjects read that the speaker was a freshman, nineteen years old, a theater major, and was involved in no University activities. Presumably, this information would make her seem as though she had not had adequate time as a student or experience at the University to be running for a student position on the Tuition Advisory Board. In addition, subjects were told her name (Anne Greeley), and her homestate (Texas, the state in which the school was located). The information regarding her homestate was provided so that her trustworthiness, or objectivity, would not be in question since she had nothing to personally gain from prohibiting a raise in tuition for out of state students. 
After participants viewed the videotape, they completed a number of attitude measures using 9-point bipolar scales. Subjects indicated the amount of interest they had in the specific topic (scale endpoints labeled "not all interested/very interested"), how likable they perceived the speaker to be (scale endpoints labeled "not at all likable/very likable"), how much skill at communication she possessed (scale endpoints labeled "very poor communication skills/very good communication skills"), and the extent to which they agreed with the speaker's position regarding prohibiting a raise in tuition for out of state students (scale endpoints labeled "disagree completely/agree completely"). The likability and communication skills measures were collected as both have shown a positive relationship with persuasion (cf. Chaiken, 1979), and may have influenced ratings of agreement with the speaker's position. A portion of the subjects $(n=80 ; 40$ female, 40 male) also indicated how trustworthy and how expert they perceived the speaker to be (scale endpoints labeled "not at all trustworthy [expert]/very trustworthy[expert]"). ${ }^{2}$

After completion of all scales in the first response booklet, subjects watched the tape again, this time without sound, so that they could focus on and evaluate the appearance of the speaker. Participants were given the second response booklet and were instructed to complete three scales placed on the first page while they were watching the videotape. These

${ }^{2} \mathrm{~A}$ check of the manipulations was taken at three points in the study. Main experiment subjects indicated their perceptions of trustworthiness and expertise in order to determine whether these perceptions affected their agreement with the speaker. A check of the credibility manipulations was taken from pretest subjects in order to examine whether perceptions of speaker expertise and trustworthiness were affected by facial appearance in absence of credibility information. However, it was also necessary to determine whether the manipulations were successful in absence of facial appearance information, as facial appearance may have affected perceptions of trustworthiness and expertise. To this end, a separate group of pilot subjects $(n=63)$ were divided into three groups (not trustworthy, not expert, and no credibility information) and merely listened to the audiotaped communication. These subjects used 9-point bipolar scales to judge the trustworthiness and expertise of the speaker. Oneway ANOVAs with trustworthiness and expertise as dependent measures achieved significance, both $F \mathrm{~s}(2,60) \geq 4.96, p \leq .01$, and thus $t$-tests were used to directly compare differences among the three conditions (comparisons reported to be significant are at $p \leq .01$ ). Those subjects who received information designed to cast suspicion on the speaker's trustworthiness found her to be significantly less trustworthy $(M=3.82)$ than subjects who received information designed to make the speaker seem inexpert $(M=5.53)$, although neither of these mean ratings was significantly different from ratings of the speaker's trustworthiness in the no information condition $(M=4.60)$. Concerning expertise, subjects in the no information condition $(M=6.05)$ and the not trustworthy condition $(M=6.09)$ found the speaker to be more expert than did subjects in the not expert condition $(M=4.67)$. Thus, the results of this pilot test indicated that the speaker was judged as less trustworthy in the not trustworthy condition as compared to the not expert condition, and that she was perceived as less expert in the not expert condition as compared to the not trustworthy condition. 
three scales required subjects to judge how old the speaker appeared to be, in years ("although you know her true age, how old does Anne Greeley look?"), rate her attractiveness (scale endpoints labeled "very unattractive/ very attractive"), and indicate how babyfaced she looked (scale endpoints labeled "very maturefaced/very babyfaced"). These measures were collected in a counterbalanced order to minimize the effects each may have exerted on the others. Age and attractiveness ratings were obtained in order to determine whether either or both of these perceptions affected the attitude measure, and the facial appearance measure was collected as a manipulation check.

\section{Results}

\section{Manipulation Checks}

In order to determine whether the speakers induced differential levels of attitude modification in absence of the credibility information, pretest subjects' ratings of agreement with the speaker (the attitude modification measure) were entered as the dependent measure in a 2(2) (Exemplar of Speaker Nested in Face Type) X 2 (Subject Sex) ANOVA. This ANOVA produced no significant main effects or interactions (all $F_{\mathrm{s}}<1$ ), indicating that neither level of facial babyishness nor individual speakers induced differential levels of attitude modification.

To ensure that subjects in the main experiment perceived that the babyfaced manipulation was successful, facial babyishness ratings were entered as the dependent measure in a 2(2) (Exemplar of Speaker Nested in Face Type) X 2 (Subject Sex) X 2 (Credibility Information Condition) between-subjects ANOVA. Only one effect was significant. As expected, speakers previously judged as babyfaced were viewed as more babyfaced $(M=5.55)$ than those judged previously as maturefaced $(M=3.74), F(1$, $112)=32.87, p<.001$.

In order to examine whether the manipulations of trustworthiness and expertise were successful, measures of speaker trustworthiness and expertise were compared. Pretest subjects were not exposed to credibility information, and thus their responses were indicative of perceptions of credibility in absence of credibility information. Although perceptions of trustworthiness for babyfaced speakers $(M=6.50)$ were higher than those for maturefaced speakers $(M=5.85)$, this difference did not reach significance, $t(38)=1.38$, ns. Similarly, judgments of expertise for maturefaced speakers $(M=6.05)$ were higher than those for babyfaced speakers $(M=5.30)$, but this difference did not obtain significance, $t(38)=1.47$, ns. 
Subjects in the main experiment also indicated perceptions of speaker trustworthiness and expertise. It was expected that questioning speaker trustworthiness would result in perceptions of trustworthiness that were lower than those in the not expert condition. Ratings of trustworthiness for babyfaced speakers in the not trustworthy condition $(M=5.65)$ were lower, although not significantly so, than ratings of trustworthiness for the babyfaced speakers in the not expert condition $(M=6.40), t(38)=1.60$, ns. However, the trustworthiness of the maturefaced speakers was not affected by credibility information, as speakers in the not trustworthy condition $(M=5.50)$ were not significantly less trustworthy than those in the not expert condition $(M=5.60), t(38)<1.00$, ns. It was also expected that questioning expertise would result in perceptions of expertise that were lower than those in the not trustworthy condition. Judgments of expertise for maturefaced speakers in the not expert condition $(M=5.75)$ were lower than were judgments of expertise for maturefaced speakers in the not trustworthy condition $(M=6.85), t(38)=2.16, p<.05$. However, the expertise of babyfaced speakers was relatively unaffected by the credibility information, as ratings of expertise for babyfaced speakers in the not trustworthy condition $(M=5.50)$ were not different than ratings of expertise for babyfaced speakers in the not expert condition $(M=5.35), t(38)<1.00$, ns. In sum, the manipulation of expertise was effective only for maturefaced speakers but not for babyfaced speakers, while the manipulation of trustworthiness was only somewhat successful for babyfaced speakers, but not for maturefaced speakers. It is likely that the facial appearance of the speakers influenced judgments of credibility, as the credibility manipulation affected perceptions of expertise for only maturefaced speakers, who presumably conveyed knowledgeability via their facial appearance, but not for babyfaced speakers, for whom expertise may never have been an issue. Similarly, perceptions of trustworthiness for maturefaced speakers were not affected by the credibility manipulation, perhaps because trustworthiness is not conveyed via the mature face. It should be noted that although the checks of the manipulations were not completely successful in the main experiment, the same manipulations were effective in absence of facial appearance information (see Note 2).

\section{Facial Babyishness, Credibility, and Attitude Change}

To test the main hypothesis that levels of facial babyishness could counteract the negative effects of questioned speaker credibility, ratings of agreement with the speaker's position were analyzed in a 2(2) (Exemplar of Speaker Nested in Face Type) X 2 (Subject Sex) X 2 (Credibility Information 
Condition) between-subjects ANOVA. This analysis did not yield a main effect for face type as subjects indicated similar levels of agreement with both babyfaced speakers $(M=6.69)$ and maturefaced speakers $(M=6.81)$, $F(1,112)<1$. Further, there was no main effect for sex of subject, $F(1$, $112)<1$. However, the credibility information $X$ face type interaction did attain significance, $F(1,112)=4.48, p<.05$. The means can be found in Table 1. Scheffé tests (alpha $=.05$ ) revealed that higher levels of agreement with the speaker's position resulted when the trustworthiness of babyfaced speakers $(M=7.22)$ was questioned than when the trustworthiness of maturefaced speakers $(M=6.03)$ was questioned. Similarly, creating doubt about expertise was less damaging to the persuasive ability of the maturefaced $(M=7.59)$ than the babyfaced speakers $(M=6.16)$.

\section{The Effects of Speaker Appearance and Demeanor}

Alternative explanations for the face and credibility effect on attitude modification may be that other aspects of the speakers' appearance (age and attractiveness), the subjects' interest in the topic, or the speakers' demeanor (likability and skill at communicating) may have affected attitude change. To assess this possibility, correlational analyses between these variables and the attitude measure were calculated. ${ }^{3}$ However, agreement

\section{TABLE 1}

Mean Agreement to Prohibit a Tuition Raise for Subjects Seeing Babyfaced and Maturefaced Communicators in the Not Trustworthy and Not Expert Conditions

\begin{tabular}{lccc}
\hline & \multicolumn{2}{c}{ Credibility Information Condition } \\
\cline { 2 - 4 } Face Type & Not Trustworthy & Not Expert & Mean \\
\hline Babyfaced & $7.22_{\mathrm{a}}$ & $6.16_{\mathrm{b}}$ & 6.69 \\
Maturefaced & $6.03_{\mathrm{b}}$ & $7.59_{\mathrm{a}}$ & 6.81 \\
Mean & 6.63 & 6.88 & \\
\hline
\end{tabular}

Note. $n$ in each cell equals 32 . Larger numbers denote more agreement with the speaker. Cells with different subscripts differ at $p \leq .05$.

${ }^{3}$ Covariance analyses were considered but rejected due to the fact that the large number of potential covariates would seriously reduce the power of the analysis. 
with the speaker's position was not significantly related to interest in the topic, liking of the speaker, or perception of the quality of the speaker's communication skills (all rs $(126) \leq .11, n s$ ).

Although agreement was not strongly related to either perceived attractiveness or age $(r s(126) \leq .08, n s)$, both of these appearance characteristics have shown a relationship with attitude modification in past research. As well, age and facial babyishness were related, $r(126)=-.47$, $p<.001$, although attractiveness and facial babyishness were not related, $r(126)=.13$, ns. As age varied with facial appearance, age judgments may have affected the attitude measure. Thus, the impact of both of these appearance variables on the attitude measure was assessed by taking a median split of each, and including it as a factor in ANOVAs with subject sex and information condition as factors and with the attitude measure as the dependent variable. The attractiveness median split ANOVA produced no significant main or interactive effects, all $F_{s}(1,120) \leq 2.16, p>.14$, indicating that the speakers' level of attractiveness did not influence attitude change for either male or female subjects in either of the manipulated information conditions. The age median split ANOVA produced only one marginally significant effect, which was the age $X$ condition interaction, $F(1,120)=3.24, p=.07$. Speakers judged as older $(M=7.12)$ in the not expert condition induced somewhat more agreement than did speakers judged as younger $(M=6.61)$ in the same condition. In the not trustworthy condition, younger speakers $(M=6.88)$ produced slightly more agreement than did older speakers $(M=6.36)$. These differences are rather small and did not obtain significance, although they are not surprising, given that perceptions of age and facial babyishness showed a negative relationship in both the not expert condition, $r(62)=-.47, p<.001$, and the not trustworthy condition, $r(62)=-.46, p<.001$. In sum, the results of the analyses with age and attractiveness did not suggest that attractiveness can account for the effects of facial appearance and credibility information on attitude modification, but that perceptions of age varied with babyishness.

\section{Discussion}

The results of this study indicate that facial appearance interacts with manipulations of speaker credibility in determining attitude change. As predicted, babyfaced speakers produced more agreement with their position when their trustworthiness was impugned than did maturefaced speakers whose trustworthiness was impugned, whereas maturefaced speakers whose expertise was questioned were more likely to produce attitude 
change than babyfaced speakers whose expertise was questioned. That is, the negative impact of questioned trustworthiness was offset by a baby face, and the negative impact of questioned expertise was similarly offset by a mature face.

Consistent with previous research (cf. Berry \& McArthur, 1986), perceived attractiveness could not account for the effects of facial appearance on attitude modification, as there was no strong relationship between this appearance variable and attitude modification. The finding that attractiveness was not related to attitude modification is inconsistent with research (e.g., Chaiken, 1979; Pallak, 1983) that has demonstrated that physically attractive people are more persuasive than unattractive people. However, in the present study, speakers who represented extreme variations in physical attractiveness were not used, and thus the impact of physical attractiveness may have been negligible when compared to the the impact of facial appearance. Not surprisingly, age ratings varied with ratings of facial appearance. Although age judgments typically vary with perceptions of babyfacedness (Berry \& McArthur, 1985; 1986), and each may have an independent effect on perceptions of others, babyfacedness has been shown to have the strongest impact of these perceptions of others (Berry \& McArthur, 1985). Moreover, subjects were told the age of the speaker, but were asked to make a judgment regarding how old she appeared ("although you know her true age, how old does Anne Greeley look?"). Asking about age in this manner may have served as the means by which the age judgments became more extreme with variations in facial appearance.

A puzzling result that emerged in this study concerns perceptions of the speakers' credibility. Two possible explanations may be offered to explain the obtained pattern of data. First, as previously noted, the presence of facial appearance as a source of information regarding trustworthiness and expertise may have influenced judgments of credibility. Maturefaced speakers, who were most likely perceived as expert, were seen as less expert when their expertise was in doubt as compared to when their knowledgeability was not in question. Babyfaced speakers, presumably viewed as trustworthy, were seen as somewhat (albeit not significantly so) less trustworthy when their motives were questioned as compared to when their honesty was not in doubt. As expertise was never an issue for babyfaced speakers, since babyfaced people don't look expert, their expertise was completely unaffected when it was questioned. In a similar manner, the maturefaced speakers didn't look honest, and thus perceptions of their trustworthiness were not affected when trustworthiness was in doubt.

Second, it is possible that subjects were not aware of, or not able to accurately articulate, the sources of their influence. Indeed, research has 
shown that people are often poor judges of the sources of their own behavior, and typically have little knowledge of what affects their attitudes (e.g., Nisbett \& Wilson, 1977; Wixon \& Laird, 1976). Thus perceptions of trustworthiness and expertise might have led to attitude change, but perceivers may have been unable to fully articulate this fact (cf. Smith, Archer, \& Costanzo, 1991).

One obvious limitation of this study concerns the fact that only females were used as speakers. As noted earlier, babyish qualities provide information about a woman's behavioral potential (Buss, 1989). However, research examining perceptions of babyfaced and maturefaced peopleboth male and female- has typically shown high concordance in trait perceptions (cf. Berry \& Brownlow, 1989). That is, babyfaced males and females are seen as weaker, warmer, and more honest than their maturefaced peers. Thus, as Berry and McArthur (1986) argue, the qualities of babies are overgeneralized to any adult who retains babyish facial features. While the present study provides an examination of these effects in an applied setting, parallel research utilizing males as speakers is warranted.

Finally, one might question the generalizability of these findings. However, one might consider the analogy of this situation to other situations that occur daily. For example, many people pay scant attention to the contents of an annoying television commercial, yet might be influenced to buy the product being promoted in that very commercial. Interest may be low, the spokesperson might be chosen due to his or her appearance, and the scene depicted may not closely resemble real life, but that annoying commercial may exert at least a minimal impact on behavior. More importantly, we don't always pay attention to what speakers are advocating even when their words should command our attention. As evidenced by the work of Abelson and his colleagues (Abelson, Kinder, Peters, \& Fiske, 1982), and Rosenberg and McCafferty (1987), people often make important decisions about political candidates not on the basis of their words, but on the basis of their appearance or a general feeling they have about them. Thus, the results of this research bring us one step closer to understanding what information contributes to these general feelings, and provides insight as to why we might give more weight to appearance than words.

\section{Acknowledgments}

This paper is based on a portion of the author's doctoral dissertation. Thanks are extended to the members of the dissertation committee, partic- 
ularly Leslie Zebrowitz. Gratitude is also expressed to Diane Berry, the women who served as speakers, and the manuscript reviewers for their numerous helpful comments. Portions of this research were presented at the Southeastern Psychological Association in March, 1991.

\section{References}

Abelson, R.P., Kinder, D.R., Peters, M.D., \& Fiske, S.T. (1982). Affective and semantic components in political person perception. Journal of Personality and Social Psychology, 42, 619-630.

Berry, D.S. (1990). Taking people at face value: Evidence for the kernel of truth hypothesis. Social Condition, 8, 343-361.

Berry, D.S., \& Brownlow, S. (1989). Were the physiognomists right? Personality correlates of facial babyishness. Personality and Social Psychology Bulletin, 15, 266-278.

Berry, D.S., \& McArthur, L.Z. (1985). Some components and consequences of a babyface. Journal of Personality and Social Psychology, 48, 312-323.

Berry, D.S., \& McArthur, L.Z. (1986). Perceiving character in faces: The impact of agerelated craniofacial changes on social perception. Psychological Bulletin, 100, 3-18.

Brownlow, S., \& Zebrowitz, L.A. (1990). Facial appearance, gender, and credibility in television commercials. Journal of Nonverbal Behavior, 14, 51-60.

Buss, D.M. (1989). Sex differences in human mate preferences: Evolutionary hypotheses tested in 37 cultures. Behavioral and Brain Sciences, 12, 1-49.

Chaiken, S. (1979). Communicator physical attractiveness and persuasion. Journal of Personality and Social Psychology, 37, 1387-1397.

Chaiken, S. (1986). Physical appearance and social influence. In C.P. Herman, M.P. Zanna, and E.T. Higgins (Eds.), Physical appearance, stigma, and social behavior. The Ontario Symposium, Vol. 3. (pp. 280-308). NY: Academic Press.

Cunningham, M.R. (1986). Measuring the physical in physical attractiveness: Quasi-experiments on the sociobiology of female facial beauty. Journal of Personality and Social Psychology, 50, 27-41.

Davis, D.K., \& Baran, S.J. (1981). Mass communication and everyday life: A Perspective on Theory and Effect. Belmont, CA: Wadsworth Publishing Company

Dion, K.K., \& Stein, S. (1978). Physical attractiveness and interpersonal influence. Journal of Experimental Social Psychology, 14, 97-108.

Eagly, A.H., \& Chaiken, S. (1984). Cognitive theories of persuasion. In L. Berkowitz (Ed.), Advances in experimental social psychology, Vol. 17 (pp. 280-308). NY: Academic Press.

Efran, M., \& Patterson, E. (1974). Voters vote beautiful: The effects of physical appearance on a national debate. Canadian lournal of Behavioral Science, 6, 352-356.

Fridlund, A. J. (1991). Evolution and facial action in reflex, social motive, and paralanguage. Biological Psychology, 32, 3-100.

Hovland, C.I., \& Weiss, W. (1951). The influences of source credibility on communication effectiveness. Public Opinion Quarterly, 15, 635-650.

McGinnies, E., \& Ward, C.D. (1980). Better liked than right: Trustworthiness and expertise as factors in credibility. Personality and Social Psychology Bulletin, 6, 467-472.

McGuire, W.J. (1985). Attitudes and attitude change. In G. Lindzey \& E. Aronson (Eds.), The handbook of social psychology, Vol. 2 (pp. 262-276). Hillsdale, NJ: Erlbaum.

Nisbett, R.E., \& Wilson, T.D. (1977). Telling more than we can know: Verbal reports on mental processes. Psychological Review, 84, 231-259.

Pallak, S. (1983). Salience of a communicator's physical attractiveness and persuasion: A heuristic versus systematic processing interpretation. Social Cognition, 2, 158-170. 
Petty, R.E., Cacioppo, J.T., \& Goldman, R. (1981). Personal involvement as a determinant of argument-based persuasion. Journal of Personality and Social Psychology, 41, 847-855.

Rosenberg, S.W., \& McCafferty, P. (1987). The image and the vote. Public Opinion Quarterly, 51, 31-41.

Smith, H.J., Archer, D., \& Costanzo, M. (1991). "Just a hunch": Accuracy and awareness in person perception. Journal of Nonverbal Behavior, 15, 3-18.

Sternthal, B., Phillips, L.W., \& Dholakia, R. (1978). The persuasive effect of source credibility: A situational analysis. Public Opinion Quarterly, 42, 285-314.

Walster, E., Aronson, E., \& Abrahams, D. (1966). On increasing the persuasiveness of a lowprestige communicator. Journal of Experimental Social Psychology, 2, 325-342.

Wixon, D.R., \& Laird, J.D. (1976). Awareness and attitude change in the forced compliance paradigm: The importance of when. Journal of Personality and Social Psychology, 34, 376-384. 
Copyright of Journal of Nonverbal Behavior is the property of Springer Science \& Business Media B.V. and its content may not be copied or emailed to multiple sites or posted to a listserv without the copyright holder's express written permission. However, users may print, download, or email articles for individual use. 